Original Research Article

\title{
Prescription pattern of patients admitted in the intensive care unit of a tertiary care hospital in Puducherry, India: a cross sectional study
}

\author{
B. Maharani ${ }^{1 *}$, A. Lourdu Jafrin'1, M. Prakash², P. Priyadarshini1
}

\begin{abstract}
${ }^{1}$ Department of Pharmacology,
${ }^{2}$ Department of Community

Medicine, Indira Gandhi

Medical College \& Research

Institute, Puducherry, India
\end{abstract}

Received: 10 November 2017

Accepted: 16 November 2017

\section{*Correspondence to: \\ Dr. B.Maharani, \\ Email: drkarthikrani \\ @gmail.com}

Copyright: (C) the author(s), publisher and licensee Medip Academy. This is an openaccess article distributed under the terms of the Creative Commons Attribution NonCommercial License, which permits unrestricted noncommercial use, distribution, and reproduction in any medium, provided the original work is properly cited.

\begin{abstract}
Background: Patients with varied demographic characteristics, admission criteria and heterogeneous group are admitted to medical Intensive Care Unit (ICU) and are usually associated with co-morbid illnesses. Instituting rational pharmacotherapy is the need of the hour for saving the life of critically-ill patients while irrational drug use may be life threatening. Drug use patterns and prescribing behaviour are the essential tools to measure drug use in health care facilities.

Methods: A record based, cross-sectional, observational study was done at medical ICU, IGMC and RI, Puducherry after obtaining IEC approval. Systemic random sampling was followed and data was collected for a period of one year. Data were analysed based on demographic characteristics, prescribing pattern and WHO drug use indicators.

Results: The data of 151 patients were analysed. Mean age of the patients admitted in ICU was 52.9 \pm 17.7 years. Percentage of male patients (57.6) admitted in ICU were more when compared to female patients (42.4). Infective etiology was the most common factor for ICU admission followed by cardiac disorders. Diabetes mellitus and hypertension were the most common co-morbidities. The average length of stay in ICU was $4.11 \pm 2.99$ days. Duration of stay in ICU ranged from $1-5$ days ( $78.8 \%$ patients) to $15-20$ days ( $0.1 \%$ patients). On an average $10.6 \pm 4.3$ drugs were prescribed for each patient. Percentage of drugs prescribed by generic name was $45.8 \%$. Majority of the drugs $(87.4 \%)$ were from essential medicine list. Antibiotics in the prescription was $13.8 \%$ and $44.4 \%$ of drugs were administered in parenteral route. The prescription was complete in 145 case sheets (96\%). Majority of the patients $(68.9 \%)$ were discharged with improvement in the condition for which they were admitted.

Conclusions: This drug utilization study has highlighted the strengths and shortcomings of the prescription pattern of patients who were admitted in the critical care setup. The information derived from this research work will be transmitted to the stakeholders for implementing the modifications wherever applicable for the betterment of the patient and the community.
\end{abstract}

Keywor ds: Alcoholic, Drug utilization, Intensive care unit, Smoking

\section{INTRODUCTION}

Patients with varied demographic characteristics, admission criteria and heterogeneous group are admitted to medical Intensive Care Unit (ICU) and are usually associated with co-morbid illnesses. ${ }^{1}$ Chronic disease and life threatening disorders among ICU patients have resulted in medicating them with drugs from different pharmacological classes, which is further complicated by the altered physiology and multi-organ system failure., ${ }^{2,3}$ Critical illness and associated co-morbid conditions alter the absorption, distribution, metabolism, excretion and plasma concentration of drugs. This in turn alters the pharmacodynamic responses which results in sub 
therapeutic, supra therapeutic or toxic effects of drugs. ${ }^{4}$ Hence, instituting rational pharmacotherapy is the need of the hour for saving the life of critically-ill patients while irrational drug use may be life threatening.

Efforts have been made by WHO to promote rational utilization of the drugs. ${ }^{5}$ Drug use patterns and prescribing behaviour are the essential tools to measure drug use in health care facilities. ${ }^{6}$

Prescribing practices of physicians can be evaluated by drug utilization study and modifications if any can be suggested. ${ }^{7}$ This will ensure quality medical care and rational pharmacotherapy.

Rational pharmacotherapy in turn helps in cost minimization and optimal utilization of available funds. Hence the present study was conducted with the following objectives.

- To assess the prescription patterns of patients admitted in ICU.

- To evaluate the drug consumption by WHO drug use indicators.

\section{METHODS}

A record based, cross-sectional, observational study was done at medical ICU, IGMC and RI, Puducherry. Data were collected for a period of 1 year (June 2016-June 2017) from the records maintained in the Medical record section (MRD).

\section{Inclusion criteria}

Case sheets of patients who were more than 18 years of age admitted to ICU for medical intensive care were included in the study.

\section{Exclusion criteria}

Case sheets with incomplete information, data of patient who stayed in the ICU for $<24$ hours and patient who was admitted in ICU for surgical or post-operative care were excluded from the study.

\section{Sample size calculation}

On an average 50 cases were admitted in the ICU every month. Considering the seas onal variation of some of the diseases, the admission in ICU in a year was divided into 3 equal parts with 4 months in each. From each of these 3 equal parts, two month's admissions were taken into account. So, the 6 months admissions in ICU was 300 .

\section{Sampling procedure}

Systematic random sampling technique (Collecting the data from every second/ alternative record) was followed and hence the sample size was 151 .

\section{Data collection}

Data on demographic characteristics, prescribing pattern, drug consumption by drug use indicators, adverse effect if any and treatment outcome were collected in a specially designed proforma. ${ }^{8}$

Prescribing pattern was analysed by:9,10

- Completeness of prescription writing. (Generic or brand name, dose, frequency of administration, route of administration, date of prescription and signature of the prescriber was considered)

Drug consumption was analysed by WHO drug use indicators : 6

- Average number of drugs prescribed.

- Percentage of drugs prescribed by generic name.

- Percentage of encounter with antibiotics prescribed.

- Percentage of encounters with an injection prescribed.

- Percentage of drugs prescribed from es sential drug list or formulary.

Adverse reactions occurred during ICU stay were also documented.

\section{Statistical analysis}

The data were entered using epidata version 3.1, data processing and analysis was done by MS Excel 2013 and SPSS 20. Continuous data were expressed as Mean \pm S.D or median (inter quartile range) wherever applicable. Categorical data were expressed as frequency and percentage wherever applicable.

\section{RESULTS}

The data of 151 patients admitted in ICU over a period of one year were analysed. Mean age of the patients admitted in ICU was $52.9 \pm 17.7$ years. Preponderance of admissions were in the age group greater than 65 years. Percentage of male patients admitted in ICU was more when compared to female patients. Majority of admitted patients were married. Nearly $21.2 \%$ of admitted patients were smokers and $43.1 \%$ of patients were alcoholic (Table 1).

Infective etiology was the most common factor for ICU admission followed by cardiac disorders (Table 2). Acute gastroenteritis, viral fever, TB meningitis, DM with sepsis, pyelonephritis, diabetic foot and septic shock were the infective etiology for which the patients were provided with ICU care. Cardiac causes ranged from acute coronary syndrome, dilated cardiomyopathy, left ventricular failure, arrhythmias and pulmonary edema. Cardiac incidence was high among female patients. Decompensated liver disease with ascites, alcoholic liver disease, hepatic encephalopathy was the hepatic reasons and it was more among male patients. Bronchopneumonia, chronic obstructive pulmonary disorders, bronchial asthma and 
pleural effusion were the pulmonary causes. Common CNS disorders for ICU admission was seizures, stroke, pontine haemorrhage, alcohol dependent seizures and encephalopathy.

Table 1: Socio-demographic profile of patients (151 patients).

\begin{tabular}{|lll|}
\hline $\begin{array}{l}\text { Bio-social } \\
\text { characteristics }\end{array}$ & $\begin{array}{l}\text { Number } \\
(\mathbf{n = 1 5 1})\end{array}$ & Percentage \\
\hline Age (years) & 30 & 19.9 \\
\hline$\leq 35$ & 21 & 13.9 \\
\hline $36-45$ & 31 & 20.5 \\
\hline $46-55$ & 31 & 20.5 \\
\hline $56-65$ & 38 & 25.2 \\
\hline$>65$ & $52.9 \pm 17.7$ & \\
\hline Mean \pm S.D & $18-90$ & \\
\hline Range & & \\
\hline Gender & 87 & 57.6 \\
\hline Male & 64 & 42.4 \\
\hline Female & & \\
\hline Marital status & 141 & 93.4 \\
\hline Married & 10 & 6.6 \\
\hline Unmarried & & \\
\hline Smoking history & 32 & 21.2 \\
\hline Smoker & 119 \\
\hline Non-smoker & 78.8 \\
\hline Alcoholic history & 65 & 43.1 \\
\hline Alcoholic & 86 & 56.9 \\
\hline Non-alcoholic & \\
\hline SD- Standard & & \\
\hline
\end{tabular}

SD- Standard deviation

Preponderance was observed in males. Renal disorders for which ICU care was provided were chronic kidney disease and hypertensive nephropathy. Few critical cases of carbamate, rat killer poison and drug over dose was also treated in ICU.

Table 2: Etiology for ICU admission.

\begin{tabular}{|c|c|c|c|c|}
\hline \multirow{2}{*}{ Diagnosis } & \multicolumn{2}{|l|}{ Sex } & \multirow{2}{*}{$\%$} & \multirow{2}{*}{ Total } \\
\hline & Male & Female & & \\
\hline Infective etiology & 17 & 17 & 22.5 & 34 \\
\hline Cardiac disorders & 9 & 16 & 16.6 & 25 \\
\hline Hepatic disorders & 20 & 4 & 15.9 & 24 \\
\hline Pulmonary disorders & 12 & 9 & 13.9 & 21 \\
\hline Electrolyte imbalance & 9 & 5 & 9.3 & 14 \\
\hline CNS dis orders & 10 & 2 & 7.9 & 12 \\
\hline Others & 6 & 5 & 7.3 & 11 \\
\hline $\begin{array}{l}\text { Chronic kidney } \\
\text { disease }\end{array}$ & 2 & 3 & 3.3 & 5 \\
\hline Acute poisoning & 2 & 3 & 3.3 & 5 \\
\hline Total & $87 *$ & $64 *$ & 100 & 151 \\
\hline
\end{tabular}

Chi-square test DOF $=5 ; *$ - value $=0.0064(<0.05)$

Diabetes mellitus and hypertension were the most common co-morbidities found among patients admitted in
ICU (Table 3). Some patients had more than one comorbid conditions.

Table 3: Associated co-morbid conditions.

\begin{tabular}{|lll|}
\hline Co-morbidity & No. of patients & Percentage \\
\hline Diabetes mellitus & 60 & 39.7 \\
\hline Hypertension & 47 & 31.1 \\
\hline $\begin{array}{l}\text { Alcoholic and } \\
\text { chronic liver disease }\end{array}$ & 8 & 5.3 \\
\hline $\begin{array}{l}\text { Chronic obstructive } \\
\text { pulmonary diseases }\end{array}$ & 6 & 3.9 \\
\hline $\begin{array}{l}\text { Coronary artery } \\
\text { disease }\end{array}$ & 2 & 1.3 \\
\hline $\begin{array}{l}\text { Chronic kidney } \\
\text { disease }\end{array}$ & 2 & 1.3 \\
\hline Others & 20 & 13.2 \\
\hline No co-morbidity & 53 & 35.1 \\
\hline
\end{tabular}

The average length of stay in ICU was $4.11 \pm 2.99$ days. Duration of stay in ICU ranged from 1-5 days $(78.8 \%$ patients) to $15-20$ days $(0.1 \%$ patients) (Table 4$)$.

Table 4: Length of ICU stay of patients.

\begin{tabular}{|lll|}
\hline Duration in days & $\begin{array}{l}\text { Number of } \\
\text { patients }(\mathbf{n = 1 5 1 )}\end{array}$ & Percentage \\
\hline $1-5$ & 119 & 78.8 \\
\hline $6-10$ & 26 & 17.3 \\
\hline $11-15$ & 5 & 3.3 \\
\hline $15-20$ & 1 & 0.6 \\
\hline Mean \pm SD & $4.11 \pm 2.99$ & \\
\hline
\end{tabular}

SD- Standard deviation

Analys is based on WHO drug use indicators had shown on an average 10.6 \pm 4.3 drugs were prescribed for each patient. Totally 1608 drugs were utilized for treating 151 patients. Percentage of drugs prescribed by generic name was $45.8 \%$. Majority of the drugs $(87.4 \%)$ were from essential medicine list. Antibiotics in the prescription was $13.8 \%$ and $44.4 \%$ of drugs were adminis tered in parenteral route (Table 5).

Table 5: WHO drug use indicators.

\begin{tabular}{|ll|}
\hline Indicator & Percentage \\
\hline Average number of drugs prescribed & 10.6 \\
\hline Percentage of generic drugs & 45.8 \\
\hline Percentage of antibiotics & 13.8 \\
\hline Percentage of Injections & 44.4 \\
\hline Percentage of drugs from EML & 87.4 \\
\hline
\end{tabular}

Nearly 221 antibiotics were utilized and cefotaxime was the most common antibiotic used followed by metronidazole (Figure 1).

Among the 151 case sheets analysed, the prescription was complete in 145 case sheets $(96 \%)$. Majority of the patients 
(68.9\%) were discharged with improvement in the condition for which they were admitted (Figure 2). Adverse events to the drug administered was noted in only one patient and the ADR was allergy to cefotaxime.

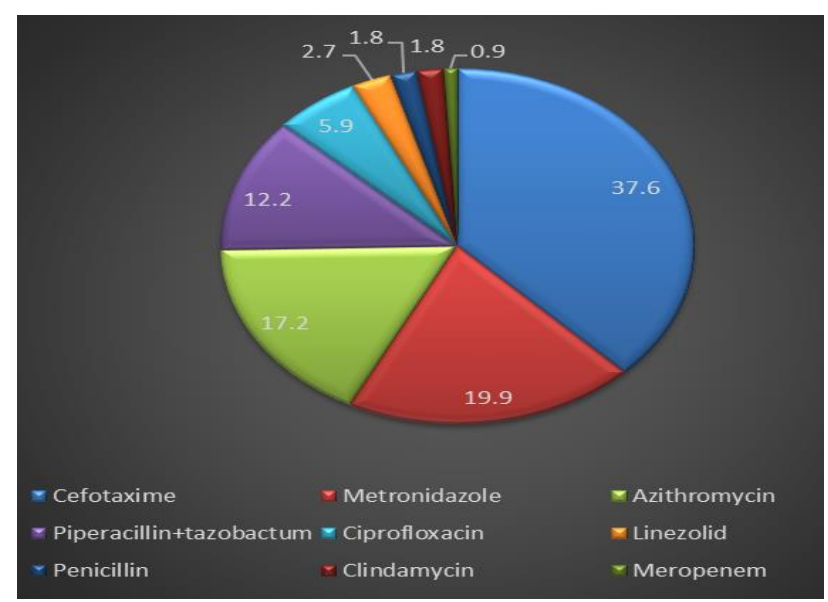

Figure 1: Antibiotics utilization percentage.

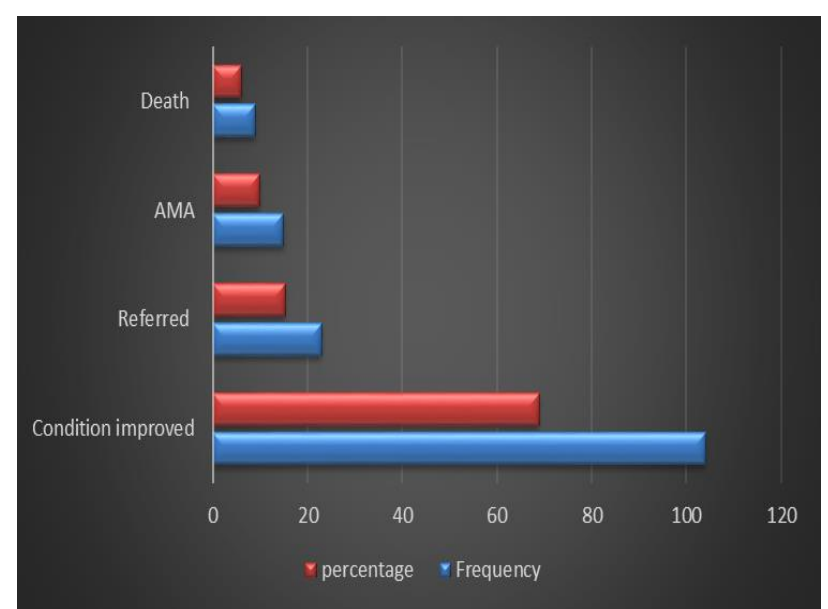

AMA - Against Medical Advise

Figure 2: Outcome of ICU stay.

\section{DISCUSSION}

Prescriptions of 151 patients admitted in ICU over a period of one year was analysed to know the prescription pattem and drug utilization pattern with special emphasis on WHO drug use indicators. Mean age of the patients admitted in ICU was $52.9 \pm 17.7$ years. Number of patients aged above 65 years admitted in ICU was more when compared to other age group and it contradicts the observation done by authors in which the admissions was more in the age group of 40-50 yrs..$^{11}$

Morbidity and mortality due to various diseases is more common in this age group because of natural process of aging and various illnesses. Nearly $43.1 \%$ of admitted patients were alcoholic and $21.2 \%$ were smokers which reflects the higher incidence hepatic disorders, pulmonary disorders and CNS disorders in males when compared to other illnesses which had higher incidence in females. Diabetes and hypertension were the two most common associated co-morbid illnesses and it is in accordance with the study done by author. ${ }^{12}$

The average length of ICU stay was $4.11 \pm 2.99$ days and majority of the patients were treated in the ICU for 1-5 days. It was in accordance with the study done by author. ${ }^{13}$ Infective etiology was the most common diagnosis in the analysed case sheets. Nearly $68.9 \%$ of the patients were discharged with improvement in the condition for which they were admitted. This indicates better health care and good prognosis of the patient.

Analys is based on WHO drug use indicators had shown on an average 10.6 \pm 4.3 drugs were prescribed for each patient. The percentage of drug used was very high when compared to other studies which were $6.35 \pm 1.56$ and $7.82 \pm 1.25$ respectively and less compared to the study $(13.54 \pm 1.6) .8,14,15$

Extensive polypharmacy may be to treat the disease per se and the co-morbidities. But the number of drugs can be kept low to avoid drug interactions, adverse reactions and reduce expenditures. Percentage of drugs prescribed by generic name was $45.8 \%$ when compared to $100 \%$ advised by WHO. ${ }^{6}$ But generic drug prescriptions was better when compared to other studies which stood around $17.9 \% .{ }^{16}$ Adhering to more generic drug prescribing helps in reducing the expenditures spent on drugs. Majority of the drugs $(87.4 \%)$ were from essential medicine list which is more compliant than WHO recommendation of $70 \% .^{6}$ Antibiotics in the prescriptions was $13.8 \%$ which was considerable less when compared to the study conducted in Karnataka (2.0\%). ${ }^{17}$ Cephalosporins and metronidazole were the more commonly used antibiotic as they cover both aerobic and anaerobic infections in ICU.

Completeness of prescription was around 96\% which indicates proper documentation of the therapy provided in the ICU. Adverse events observed during the study period was negligible.

This study has few limitations. It was conducted in a single centre, so the results cannot be extrapolated to the general population. Drug interaction among the prescribed drugs was not accounted. Pharmacoeconomic calculation of expenditures was not done.

\section{CONCLUSION}

This drug utilization study has highlighted the strengths and shortcomings of the prescription pattern of patients who were admitted in the critical care setup. This has also highlighted the differences in patient care in different parts of India as well as globally. The information derived from this research work will be transmitted to the stakeholders for implementing the modifications wherever applicable for the betterment of the patient and the community. 


\section{ACKNOWLEDGEMENTS}

Authors would like to thank Medical Record Section, IGMC and RI for their valuable help in data collection.

Funding: No funding sources

Conflict of interest: None declared

Ethical approval: The study was approved by the Institutional Ethics Committee

\section{REFERENCES}

1. Lisha JN, Padmini D, Shobha G. Cardiovascular medications among the critically ill patients of a tertiary care hospital: A drug utilization study. J Pharmacol Pharmacother. 2013;4(4):285-87.

2. Smythe MA, Melendy S, Jahns B. An exploratory analysis of medication utilization in a medical intensive care unit. Crit Care Med. 1993;21(9):319-23.

3. John LJ, Devi P, John J, Arifulla M, Guido S. Utilization patterns of central nervous systemdrugs:A cross sectional study among the critically ill patients. J Neurosci Rural Pract. 2011;2:119-23.

4. Townsend PL, Reynolds JR, Zaske DE. Applied Pharmacokinetics in the Intensive care unit. In: Intensive care Medicine. $4^{\text {th }}$ Ed. Philadelphia. Lippincott-Raven Publishers. 1999;1413.

5. Laing RO. Rational drug use: an unsolved problem. Trop Doct. 1990;20:101-3.

6. World health organization. How to investigate drug use in health facilities. 1993. Available at: http://apps.who.int/medicinedocs/en/d/Js2289e/. Accessed 22 July 2016.

7. Dukes MNG, World Health Organization, editors. Drug utilization studies: methods and uses. Copenhagen: World Health Organization, Regional Office for Europe. 1993:218.

8. Nibrad VV, Nayak BB, Raul AR, Vijayprasad S, Vakade KP, Jadhav AR, et al. Drug Utilization Pattern in Medical Intensive Care Unit (MICU) in a Tertiary Care Teaching Hospital in Rural Area of Maharashtra. Int J of App Bio and Pharma Tech. 2015;6(1):148-53.

9. Ansari KU, Singh S, Pandey RC. Evaluation of prescribing pattern of doctors for rational drug therapy. Indian J Pharmacol. 1998;30:43-6.
10. Calligaris L, Panzera A, Arnoldo L, Londero C, Quattrin R, Troncon MG, et al. Errors and omissions in hospital prescriptions: a survey of prescription writing in a hospital. BMC Clin Pharmacol. 2009; 13:9.

11. Pichala PT, Kumar BM, Zachariah S, Thomas D, Saunchez L, Gerardo AU. An interventional study on intensive care unit drug therapy assessment in a rural district hospital in India. J Basic Clin Pharm. 2013;4(3):64-7.

12. Dawalji S, Venkateshwarlu K, Thota S, Venisetty PK, Venisetty RK. Prescribing pattern in coronary artery disease: A prospective study. Int J Pharm Res Rev. 2014;3(3):24-33.

13. Tavallaee M, Fahimi F, Kiani S. Drug-use patterns in an intensive care unit of a hospital in Iran: an observational prospective study. Int J Pharm Pract. 2010;18(6):370-6.

14. Muhit MA, Rahman MO, Raihan SZ, Asaduzzaman M, Akbar MA, Sharmin N. Cardiovascular disease prevalence and prescription patterns at a tertiary level hospital in Bangladesh. J Appl Pharm Sci. 2012;2(3):80-4.

15. Patel MK, Barvaliya MJ, Patel TK, Tripathi C. Drug utilization pattern in critical care unit in a tertiary care teaching hospital in India. Int $\mathbf{J}$ Crit Ill Inj Sci. 2013;3(4):250-5.

16. Shobha P, Mes saline S. Evaluation of rational drug use pattern using WHO prescribing indicators in a medical intensive care unit of a tertiary teaching hospital in Kerala, India. International Journal of Basic \& Clinic al Pharmacology. 2017;6(6):1328.

17. Jacob J, Thomas C, Naaz A, Ramasamy R, Nazeem T, Shekar S. Study of Prescription Pattern in an intensive care unit: A prospective observational study. World J of Pharmacy and Pharmaceutical Sciences. 2015;5(1):1125-32.

Cite this article as: Maharani B, Jafrin AL, Prakash M, Priyadarshini P. Prescription pattern of patients admitted in the intensive care unit of a tertiary care hos pital in Puducherry, India: a cros s sectional study. Int J Basic Clin Pharmacol 2017;6:2822-6. 